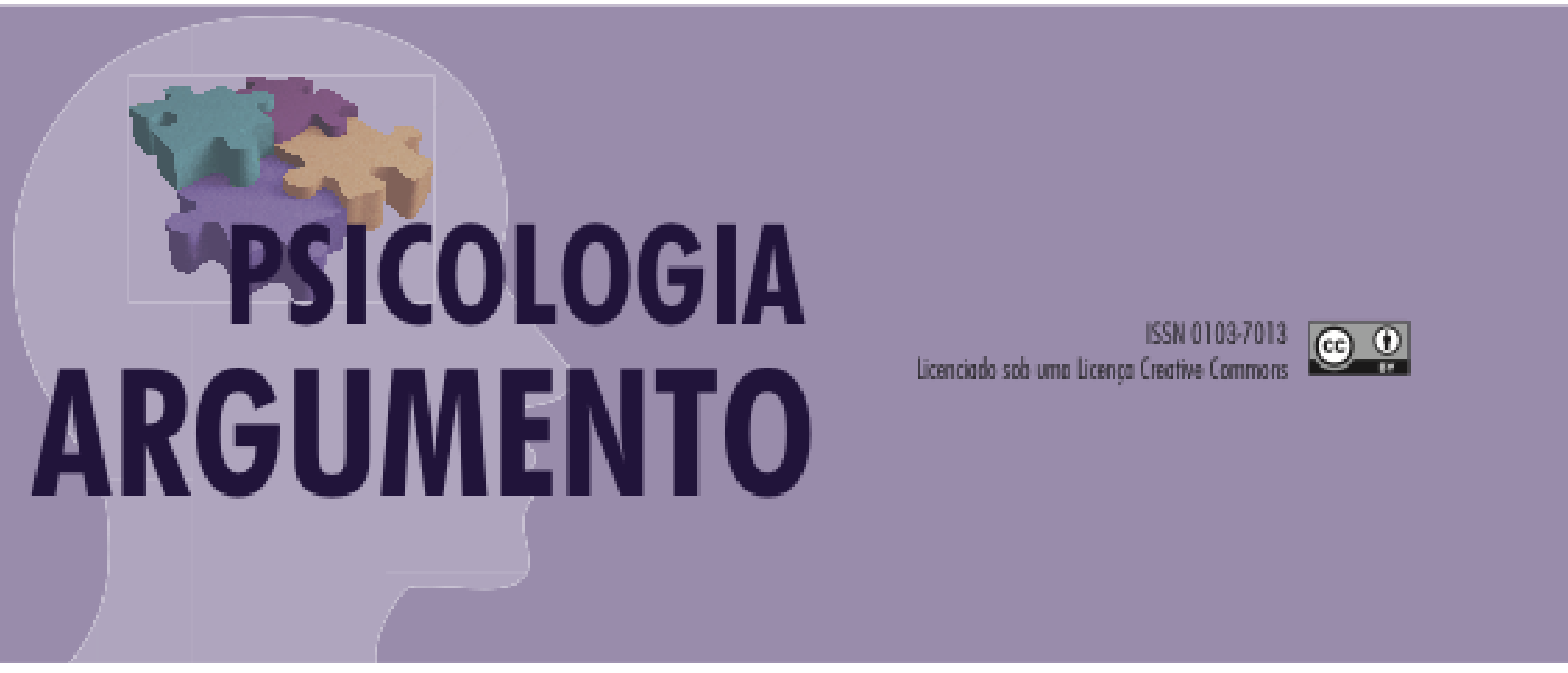

doi: http://dx.doi.org/10.7213/psicolargum.36.94.AO04

\title{
"Missão dada, missão cumprida": Vivências de prazer e sofrimento no trabalho de desenvolvedores de TI
}

\section{"A mission given is a mission accomplished": Experiences of pleasure and} suffering at work of IT developers

\begin{abstract}
Viviane de Souza Buriol
Mestre em Psicologia da Universidade do Vale do Rio dos Sinos, São Leopoldo, Rio Grande do Sul - Brasil, email vivianeburiol@terra.com.br

Patrícia Henrich

Graduanda de Psicologia da Universidade do Vale do Rio dos Sinos, São Leopoldo, Rio Grande do Sul - Brasil, email psicohenrich@gmail.com

\section{Janine Kieling Monteiro}

Professora Doutora do PPG de Psicologia da Universidade do Vale do Rio dos Sinos, São Leopoldo, Rio Grande do Sul - Brasil, email janinekm@unisinos.br

\section{Cristiane Barros Marcos}

Doutoranda de Psicologia da Universidade do Vale do Rio dos Sinos, São Leopoldo, Rio Grande do Sul - Brasil, email cristianemarcos@gmail.com
\end{abstract}

\footnotetext{
Resumo

A área de tecnologia da informação (TI) é um campo que cada dia se torna mais essencial para a sobrevivência da economia. Neste contexto, o trabalhador de TI precisa ser dinâmico e estar conectado full time para atender às tarefas laborais. Diante deste cenário, este estudo objetivou compreender as vivências de prazer e sofrimento no trabalho de profissionais da área de TI, sob
} 
a teoria da Psicodinâmica do Trabalho, analisando a organização do trabalho e seus impactos para a saúde mental. O delineamento utilizado foi descritivo, com abordagem qualitativa. Participaram da pesquisa 10 desenvolvedores de software, de uma empresa prestadora de serviços de TI da Região Metropolitana de Porto Alegre/RS. Os instrumentos utilizados foram uma entrevista individual e um questionário sociodemográfico e laboral. A análise do material foi realizada através da análise de conteúdo. A empresa que os entrevistados trabalhavam adotava uma estrutura de trabalho de outsourcing, o que para estes profissionais era atraente e desafiador, exigindo dinamismo e proatividade. Os profissionais sentiam prazer pela identificação e constante desafio na atividade que desenvolviam, bem como pelo reconhecimento no serviço prestado. $\mathrm{O}$ sofrimento foi referido pela baixa remuneração e pelo dinamismo da área da TI, que envolve velocidade, constante mudança, alta demanda de trabalho e responsabilidades. Diante disto, identificou-se a necessidade de investir no reconhecimento do trabalhador, no fortalecimento da cooperação e de espaços de discussão genuínos, visando à promoção da saúde mental.

Palavras-chave: psicodinâmica do trabalho; profissionais de TI; prazer-sofrimento; saúde mental.

\begin{abstract}
The information technology (IT) area is a field that everyday becomes more essential for the economy survivor. In this context, the IT employee needs to be dynamic and full time connected to reach the labour tasks. In face of this scenario, the present study aimed to comprehend the experiences of pleasure and suffering at work of IT professionals, under the Psychodynamics of Work theory, analysing the work organization and its impacts on mental health. The design used was descriptive, with qualitative approach. Ten software developers of an IT service company from the metropolitan region of Porto Alegre/RS participated in the survey. The instruments used were individual interview and sociodemographic and labour questionnaire. The data analysis was performed by content analysis. The company that the interviewees worked for had an outsourced work structure, which for these professionals was attractive and challenging, requiring dynamism and proactivity. The professionals feel pleasure by the identification and constantly challenges in their activities, as well as the recognition in the service provided. The suffering was referred to the low pay and dynamism in IT area, which involves velocity, constantly changes, higher work demand and responsibilities. Faced with these circumstances, has identified the necessity to invest in the employee recognition, strengthening cooperation and genuine forums, aiming to develop the mental health.
\end{abstract}

Keywords: psychodynamics of work; IT employees, pleasure-suffering mental health.

\title{
Resumen
}

El área de tecnología de la información (TI) es un campo que cada día se vuelve más esencial para la supervivencia de la economía. El trabajador de TI necesita ser dinámico y estar conectado a tiempo completo para atender las tareas de trabajo. Este estudio objetivó comprender las vivencias de placer y sufrimiento en el trabajo de profesionales del área de TI, bajo la teoría de la PdT, analizando la organización del trabajo y sus impactos para la salud mental. El delineamiento utilizado fue descriptivo, con abordaje cualitativo. Participaron de la investigación 10 desarrolladores que actuaban en fábrica de software, de una empresa prestadora de servicios de TI la región de Porto Alegre/RS. Los instrumentos utilizados fueron entrevista individual y cuestionario sociodemográfico y laboral. El análisis del material fue realizado a través del análisis de contenido de Bardin. La empresa que los encuestados trabajan está orientada a la estructura de trabajo de 'outsourcing', lo que para estos profesionales es atractivo y desafiante, exigiendo dinamismo y proactividad. Los profesionales sienten placer por la identificación y constante desafio en la actividad que desarrollan, así como por el reconocimiento en el servicio prestado. El sufrimiento es referido por la baja remuneración y el 
dinamismo del área de la TI, que implica velocidad, constante cambio, alta demanda de trabajo y responsabilidades. En este sentido, se identificó la necesidad de invertir en el reconocimiento del trabajador, en el fortalecimiento de espacios de discusión genuinos y de la cooperación, buscando la promoción de la salud mental.

Palabras clave: psicodinámica del trabajo; profesionales de TI; placer-sufrimiento; salud mental.

\section{Introdução}

O campo da Tecnologia da Informação (TI) vem se tornando cada dia mais essencial à sobrevivência de qualquer setor da economia e da vida moderna. As mudanças atuais no mundo do trabalho provocam um impacto na vida dos indivíduos, alterando de forma significativa a relação do homem com o trabalho. $\mathrm{Na}$ era da conectividade e interatividade, esta relação apresenta novas dimensões e tendências - diariamente o trabalhador de TI é desafiado a produzir softwares de forma criativa, utilizando-se de suas capacidades intelectuais em um ambiente flexível, dinâmico, inovador e em constante transformação (Pacheco, Pereira Jr., Pereira, \& Pereira Filho, 2005).

Diante do dinamismo da área de TI, tudo se torna urgente. Com a necessidade de estar conectado full time ao trabalho, por meio de aparatos tecnológicos, para atender às exigências das demandas de trabalho, o trabalhador exerce longas horas de jornada laboral, e, por vezes, o trabalho passa a ser um elemento conflituoso (Ferreira, 2006). Neste contexto, o lema que dita à produtividade é missão dada, missão cumprida, havendo, devido à sobrecarga de trabalho, um acúmulo de tensão.

O crescimento rápido da área de TI contribui para a intensidade nas competições do mercado de trabalho. Este crescimento cria novas necessidades e modelos ideiais de profissionais de TI, no qual sejam mais especializados e tenham maior competência as atribuições exigidas. A atividade de desenvolvimento de software é fortemente marcada pela imaterialidade de seus resultados, bem como a criatividade e motivação exigida dos trabalhadores (Lima \& Oliveira, 2017). Como resultado, os profissionais de TI tendem a ser submetidos a cargas adicionais de tensão, trabalhos precários, desterriorização do posto de trabalho, descaracterização do tempo de lazer (Rosenfield, 2011).

Partindo deste cenário, o presente estudo tem como foco a questão: Quais são as características do contexto de trabalho dos trabalhadores da área de TI e as suas 
implicações na saúde mental? A análise proposta neste estudo será norteada pelo referencial teórico da Psicodinâmica do Trabalho (PdT). Nesta perspectiva, objetiva-se descrever a organização do trabalho e as vivências de prazer e sofrimento destes trabalhadores nas atividades laborais.

A teoria da PdT é uma abordagem capaz de explicar os efeitos do trabalho sobre os processos de subjetivação, as patologias sociais e a saúde mental dos trabalhadores. Desta forma, a PdT, ao buscar a normalidade do trabalhador, passa a considerar vários aspectos, tanto de caráter objetivo, como a organização do trabalho, quanto de caráter subjetivo do indivíduo, como as vivências de prazer e sofrimento, que ocorrem na interação entre o contexto do trabalho e a dinâmica interna do trabalhador (Merlo, 2015).

A Organização do Trabalho (OT) refere-se à divisão das tarefas - conteúdo, ritmo e trabalho prescrito versus real - e à divisão dos homens - relações de responsabilidade, hierarquia e poder (Dejours, 2008). Há, assim, uma relação complexa e singular entre a OT e a subjetividade do trabalhador, que pode auxiliar a compreender a dinâmica entre o prazer e o sofrimento no trabalho e tende a interferir em sua vida psíquica.

O trabalho prescrito abarca o que é predeterminado, fixado e que deve ser realizado, já o trabalho real envolve as particularidades do trabalho vivo com ajustes da função e da reorganização do trabalhador (Dejours, 2008). Quando o sujeito não consegue usar sua criatividade, dar significado ao trabalho e lidar com o real do trabalho, ocorrem conflitos, potencializando o sofrimento e as patologias relacionadas ao trabalho (Dejours, 2004).

Ressalta-se, contudo, que o sofrimento faz parte da condição humana e pode ser uma potência para transformar a realidade (Mendes, 2007), de modo que sua ausência não é sinônimo de saúde, já que são as capacidades internas e externas dos sujeitos em elaborar e enfrentar o sofrimento que podem gerar saúde mental. A mobilização subjetiva transforma o sofrimento no trabalho em uma fonte de prazer, permitindo que o trabalhador se engaje no trabalho, utilizando sua subjetividade e sua criatividade para transformar as situações dolorosas em prazer (Mendes, 2007).

A PdT propõe um método, de pesquisa ação, alinhado à clínica do trabalho, no qual é propiciada uma escuta clínica aos trabalhadores. Já que "Falar do sofrimento leva o trabalhador a se mobilizar, pensar, agir e criar estratégias para transformar a 
organização do trabalho" (Mendes, 2007, p. 31). Tal cenário requer um olhar detalhado sobre o contexto de trabalho em que estão inseridos os trabalhadores da área de TI, justificando o presente estudo. Este visa conhecer com maior profundidade a relação entre trabalho e saúde mental deste grupo de trabalhadores, ainda pouco investigada. Para tanto, tem-se como objetivos: a) Descrever a organização do trabalho de trabalhadores da área de TI vinculados a uma empresa privada da região metropolitana de Porto Alegre; b) Conhecer as vivências de prazer e sofrimento do grupo em foco.

\section{Método}

Este estudo possui delineamento descritivo e abordagem qualitativa. Devido à especificidade do trabalho e do esforço envolvido é necessário penetrar na vivência do trabalhador. As dimensões psíquicas e intelectuais residem na experiência, no registro da vivência, no que também é chamado de experiência subjetiva do trabalho (Dejours, 2008).

\section{Participantes}

Participaram deste estudo dez trabalhadores da área de TI de uma empresa privada da região metropolitana de Porto Alegre/RS, selecionados por conveniência. Os critérios de inclusão foram: possuir mais de 18 anos, estar atuando na função de desenvolvedor de software, estar mais de 6 meses na empresa. Os participantes possuíam de 21 a 38 anos, sendo duas mulheres e oito homens, todos possuíam vínculo da CLT, com formação superior. Os dados sociodemográficos e laborais estão apresentados na tabela 1 .

O desenvolvedor de software é responsável por construir aplicações através de códigos, atua como desenvolvedor de soluções tecnológicas, podendo ser considerado um arquiteto de informação. Esta categoria de profissionais necessita ser hábil, ter conhecimentos sobre lógica de programação e lógica do negócio. Os sistemas de tecnologia são criados para facilitar os processos organizacionais, desta forma, a atuação destes profissionais torna-se relevante, pois compreendem, executam e resolvem disfunções e panes (Pinheiro, 2011). 
Tabela 1

Apresentação dos dados sociodemograficos laboral

\begin{tabular}{|c|c|c|c|c|c|}
\hline Sujeito & Formação & Idade & Estado Civil & Filho & Tempo de Atuação \\
\hline P. 1 & Sistemas da Informação & 27 & Solteiro & 0 & 6 anos e 6 meses \\
\hline P. 2 & $\begin{array}{c}\text { Tecnólogo em Análise de } \\
\text { Sistemas }\end{array}$ & 22 & Casado & 0 & 1 ano e 3 meses \\
\hline P. 3 & Ciência da Computação & 32 & Casado & 0 & 7 anos \\
\hline P. 4 & Sistemas para Internet & 29 & Casado & 0 & 1 ano e 5 meses \\
\hline P. 5 & $\begin{array}{c}\text { Tecnólogo Sistemas para } \\
\text { Internet }\end{array}$ & 23 & Casado & 0 & 1 ano e 1 mês \\
\hline P. 6 & $\begin{array}{c}\text { Tecnólogo Sistemas para } \\
\text { Internet }\end{array}$ & 24 & Casado & 0 & 1 ano e 3 meses \\
\hline P.7 & $\begin{array}{l}\text { Sistemas da Informação } \\
\text { (andamento) }\end{array}$ & 25 & Casado & 0 & 3 anos \\
\hline P. 8 & $\begin{array}{l}\text { Sistemas da Informação } \\
\text { (andamento) }\end{array}$ & 32 & Casado & 1 & 1 ano e 1 mês \\
\hline P. 9 & Sistemas da Informação & 38 & Solteiro & 0 & 3 anos \\
\hline P. 10 & $\begin{array}{c}\text { Análise dos Desenvolvimento } \\
\text { de Sistemas }\end{array}$ & 21 & Solteiro & 0 & 8 meses \\
\hline
\end{tabular}

Fonte: Elaborado pela autora.

\section{Instrumentos}

Os instrumentos utilizados neste estudo foram um questionário sociodemográfico e laboral e uma entrevista semiestruturada. O questionário foi utilizado para caracterizar os participantes e continha informações como: idade, sexo, escolaridade, estado civil, tempo de trabalho, função e possíveis afastamentos do trabalho. A entrevista foi organizada com base em um roteiro prévio, abordando aspectos relacionados às vivências de prazer e sofrimento no trabalho, à organização do trabalho e ao processo saúdeadoecimento, segundo a PdT.

\section{Procedimentos de Pesquisa}

Entrou-se em contato com a empresa de TI RGB (nome fictício) para a apresentação do estudo aos Recursos Humanos (RH). Após aprovação do projeto pela 
companhia, foi realizado o convite aos participantes por meio de e-mails disponibilizados pelo RH da empresa, conforme critérios de inclusão dimensionados na pesquisa. Ao todo foram contatados os 15 profissionais na empresa que se enquadravam nos critérios de inclusão, dos quais cinco se recusaram a participar. Para aqueles que aceitaram o convite, foi realizado um contato, via telefone, para agendar a entrevista conforme a sua disponibilidade. As entrevistas ocorreram no período de janeiro a março de 2017, com duração média de 1h30min, em salas reservadas nas dependências do local de trabalho.

A pesquisa atendeu às normas dos procedimentos éticos, conforme resolução $n^{0}$ 510/2016 do Conselho Nacional de Saúde (CNS), e foi aprovada pelo Comitê de Ética CAAE $n^{\circ}$ 62606016.7.0000.5344 em Pesquisa da Universidade do Vale do Rio dos Sinos - UNISINOS. Aos participantes foi lido e entregue o Termo de Consentimento Livre e Esclarecido (TCLE). Após o aceite dos mesmos, as entrevistas foram gravadas, transcritas e analisadas na íntegra com base na análise de conteúdo, conforme proposta por Bardin (1994).

A análise ocorreu em dois momentos: primeiramente realizou-se uma leitura minuciosa e, no segundo momento, buscou-se categorizar as falas dos participantes utilizando categorias a priori, a partir do referencial teórico da PdT. O material foi analisado por dois juízes para avaliar a concordância na categorização e, posteriormente, nas situações discordantes utilizou-se um terceiro juiz. Este procedimento favorece a garantia da confiabilidade da categorização (Castro, Abs \& Sarriera, 2011). As categorias estabelecidas a priori foram: organização do trabalho; vivências de prazer e de sofrimento, conforme Tabela 2, desmembradas em subcategorias. 
Tabela 2

Apresentação das Categorias e Subcategorias

\begin{tabular}{|c|c|}
\hline Categorias & Subcategorias \\
\hline \multirow{4}{*}{ Organização de Trabalho } & 1. Outsourcing \\
\hline & 2. Autogestão do Trabalho \\
\hline & 3. Trabalho em equipe \\
\hline & 4. Valorização do Conhecimento \\
\hline \multirow{3}{*}{ Prazer } & 1. Identificação com o trabalho \\
\hline & 2. Utilidade do trabalho \\
\hline & 3. Reconhecimento dos clientes e da profissão \\
\hline \multirow{5}{*}{ Sofrimento } & 1. Sobrecarga de Trabalho \\
\hline & 2. Pressão por resultados \\
\hline & 3. Controle \\
\hline & 4. Condições de trabalho deficientes \\
\hline & 5. Falta de Reconhecimento financeiro \\
\hline
\end{tabular}

Fonte: Elaborado pela autora.

\section{Resultados e discussão}

1 - Organização do Trabalho

A organização do trabalho engloba a divisão das tarefas e a divisão dos homens (Dejours, 2008), envolvendo um paradoxo entre o trabalho prescrito e o trabalho real. Baseados nas falas dos participantes se construiu a análise do trabalho real vivenciado pelos profissionais da área de Tecnologia da Informação. O trabalho real envolve as particularidades do trabalho realizado pelo profissional, que ajusta, reorganiza e adapta os processos fixados pelo trabalho prescrito (Dejours, 2008).

\section{2 - Outsourcing}

A companhia pesquisada tem uma proposta de serviço atual de outsourcing, que é um tipo de terceirização estratégica de áreas-chave para os negócios (Almeida, Batista, \& Cabral, 2015). Esta presta serviços vinculados à área de TI para vários clientes que demandam desta nova estrutura de trabalho. Dentro do contexto da OT, os profissionais entrevistados expressaram que suas atividades consistem em "[...] basicamente eu 
trabalho nos desenvolvimentos de software especificamente na área de banco, consiste na base em trabalho em projetos" (Participante 7).

Esta dinâmica de trabalho é relacionada ao serviço que a empresa presta de outsourcing, projetos com tempos determinados e prazos para o seu cumprimento. $\mathrm{O}$ cliente contrata trabalhos de empresas que terceirizam o serviço especializado para a execução:

"[...] nas empresas, ela tem uma necessidade muito grande de uma consultoria de especialistas com software, a Empresa RGB vende isso." (Participante 7)

"Quanto ao serviço em si, a empresa à qual presta serviço, isso tu vê como um porto seguro. Tu tá ali pra resolver, é a solução. Se eles tivessem a solução, não precisariam de um terceiro. Então tu tá ali pra mostrar que a empresa que tu trabalha, que tu representa tem a solução pro que eles precisam, tu é o cara que resolve." (Participante 8)

A denominação de outsourcing no inglês significa "fonte de fora", tem como objetivo obter a mão-de-obra das atividades-meio de fora da empresa (Silva \& Siluk, 2007). A consultoria de TI RGB (nome fictício) é responsável por desenvolver as atividades meio das empresas contratantes, trabalhando em conjunto para sustentar o negócio. Este trabalho em conjunto é apresentado como complexo, burocrático e rígido (com pouca margem de negociação) pelos entrevistados:

“[...] na verdade isso é uma questão meio complicada, assim, como prestador de serviço a gente gosta sempre de entregar o melhor trabalho possível e ser reconhecido por isso. Só que muitas vezes é bem difícil, porque dentro dessa estrutura existem muitas pessoas, muitos cargos e, às vezes, um pouco de burocracia. [...]A gente presta serviço para outras pessoas então a gente tem que fazer da maneira que agrada o cliente e não a nossa." (Participante 6)

"[...] se o cliente decidiu que é assim tem que ser feito, assim se tipo por mais que entre em concessões, discussões, no final das contas o desenvolvedor faz aquilo que falam pra ele fazer. E nem sempre as coisas são feitas da maneira mais certa possível, o que gente aprende." (Participante 10)

Apesar da estrutura de trabalho ser diferenciada e ter elevados patamares de tecnologia, a produção de trabalho continua sendo similar a que regia no século XIX as relações de trabalho são movidas pela lucratividade e capital (Franco, Druck, \& Seligmann-Silva, 2010). A tática do negócio outsourcing é relacionada à redução de 
tempo na execução das atividades-meio, no qual a responsabilidade é da empresa contratada (Almeida et al, 2015).

A temática terceirização tem gerado vários debates, devido às novas reestruturações de trabalho, onde frequentemente há a preocupação desta forma de vinculação acarretar a precarização das condições de trabalho e dos direitos dos trabalhadores (Franco et al, 2010; Almeida et al, 2015). No entanto, o contexto de trabalho dos profissionais da fábrica de softwares da empresa RGB é descrito como uma opção de serviço especializado e qualificado e, neste caso, valorizado no segmento dos negócios. Os participantes descreveram o seu trabalho terceirizado como sendo diferenciado, pois os mesmos permanecem dentro da empresa RGB, frequentando algumas vezes a empresa contratante. Este aspecto favorece o sentimento de pertencimento e reconhecimento social dos profissionais, que são identificados dentro da organização (Dejours \& Abdoucheli, 1994).

Os entrevistados relatam como é para eles, atuar em uma empresa que presta serviço:

"Pra mim acho que é uma forma bem tranquila, estando aqui dentro da fábrica é legal. Mas quando eu entrei aqui eu ficava dentro do cliente aí eu tinha pouco envolvimento com a fábrica entendeu? Pegava eu vinha pra cá 1,2 vezes por semana. Tipo às vezes, o pessoal nem me conhecia sabe [...], tu não tem muito vínculo assim sabe. Mas está trabalhando aqui é legal na questão de fábrica, porque tu está sempre pulando de cliente em cliente, sempre está vendo projetos diferentes, tu acaba vendo tecnologias novas, vendo cenários diferentes, projetos diferentes." (Participante 1)

"[...] a gente não tem tanto contato dentro da empresa do cliente né, porque a gente não costuma ir muito pra lá." (Participante 4)

Tendo isto em vista, o trabalhador analista desenvolvedor de softwares, quando atua dentro da empresa que foi contratado, sente-se vinculado e acolhido. A OT da empresa RGB funciona na lógica de know-how, que foca em um conhecimento e experiência sobre algo (Almeida et al, 2015). Este prisma vem sendo considerado como um recurso avançado da empresa moderna (Silva \& Siluk, 2007), pela redução de custos, aumento da produtividade, que o outsourcing propicia às empresas (Almeida et al, 2015). 
3 - Autogestão do Trabalho

Os profissionais precisam assegurar o processo de trabalho, cabe a eles a autogestão do tempo e das tarefas, para cumprirem os prazos determinados pelos contratos com o cliente. A liberdade e autonomia foram aspectos apontados pelos entrevistados como algo positivo no contexto laboral, onde possuem flexibilidade de horários e receptividade dos superiores, como relatado nas falas:

“[...] todos eles me deram liberdade, nunca tive a situação de digamos assim de um líder ser mais fechado, até pelo ambiente que a gente acaba se tornando ali de liberdade de falar, de discutir, de brincar, acaba tendo essa relação mais aberta." (Participante 7)

"[...] gosto das liberdades, aqui se eu precisar sair em algum momento e depois só preciso justificar as minhas horas, é bem tranquilo eu gosto disso também." (Participante 4)

\section{4 - Trabalho em Equipe}

A dinâmica que se estabelece entre as relações de trabalho, caracterizadas pela autogestão dos profissionais e pela abertura dos superiores, mobiliza a interação social, que pode favorecer a cooperação, a solidariedade e confiança (Dejours \& Abdoucheli, 1994). Para os entrevistados, o trabalho de desenvolvedor de software, necessita-se do trabalho em equipe, para que possam trocar seus conhecimentos. Torna-se fundamental a interação entre seus pares, como se percebe na fala:

"[...] é muito importante tu ter uma equipe, trabalhar sozinho é algo que vai te deixar um pouco preso a tua visão de mundo. Então tu trabalhar com uma equipe é importante pra que tu veja a opinião das outras pessoas, saiba das opiniões das outras pessoas e que elas possam apontar aonde tu tá errando." (Participante 6)

“[...] a nossa reunião diária com o cliente e com toda a equipe pra dizer o que a gente teve no dia anterior o que a gente vai fazer nesse dia, se teve algum problema que daí eles possam resolver. Isso é legal porque tu tem o contato diário com o cliente que eu acho isso importante, porque ele deixa muito mais próximo pra ti resolver problemas muito rápido sem ter que ficar esperando por outras pessoas." (Participante 4) 
A técnica adotada na equipe de ter reuniões diárias sobre o processo de trabalho estimula a comunicação contínua entre os profissionais. Como também auxilia na solução dos problemas laborais. Ao ajustar os conflitos, reduzindo a sua frequência, favorece relações saudáveis. Para Dejours (2011), a saúde mental está relacionada à qualidade das relações de trabalho e cooperação dos colegas.

\section{5 - Valorização do Conhecimento}

Neste contexto, está presente a busca constante de atualização e de qualificação por meio de novas tecnologias, na tentativa de acompanhar a velocidade das mudanças. É possível afirmar, então, que o trabalho na área de TI torna o sujeito um empreendedor de si mesmo. O sujeito necessita ter busca incansável de capacitação profissional e tecnológica, visando potencializar a produção de softwares e exigindo o exercício constante da criatividade individual do trabalhador. Esta percepção é apresentada pelo participante:

"[...] eu tô trabalhando pro cliente $X$, que tem diversos sistemas, diversas tecnologias. Eles procuram sempre tá atualizados, mas ainda têm coisas muito antigas, então todos os dias eu tenho que tá aprendendo algo novo. [...]. [...] às vezes, a gente tem que pensar em soluções mirabolantes pra conseguir resolver problemas que eles nos passaram. Teve algumas/alguns projetos que eu fiz aqui também que eu precisei desenvolver totalmente a minha criatividade." (Participante 4)

Desta forma, as fronteiras entre local de trabalho e vida pessoal e social do trabalhador em TI não são nítidas, havendo um paradoxo entre a liberdade, as metas, os prazos e o excesso de jornada de trabalho diário. A subjetividade do trabalhador e as suas conexões com o trabalho implicam, assim, refletir sobre o modo como as experiências do labor influenciam no modo de agir, pensar, sentir e trabalhar destes sujeitos (Tittoni \& Nardi, 2011).

\section{6 - Prazer}

O prazer, assim como o sofrimento, é constitutivo da subjetividade no trabalho. As vivências de prazer surgem do bem que o trabalho produz no corpo, na mente e nas relações sociais e constituem-se como um dos indicadores de saúde no trabalho por 
viabilizarem a estruturação psíquica, a identidade e a expressão da subjetividade (Freitas \& Facas, 2013).

\section{7 - Identificação com o Trabalho}

Os trabalhadores da área de TI relacionaram o prazer nas suas atividades laborais à sua identificação com o trabalho. Relataram gostar da área em que atuam e das atividades desenvolvidas, demonstrando interesse:

“[...] Eu trabalho porque eu gosto, eu gosto do que faço e meu objetivo é entregar o melhor possível." (Participante 1)

"[...] Eu gosto muito do que eu faço, eu sempre gostei de tecnologia, sempre gostei de dessa área e quando eu conheci o desenvolvimento de software eu vi que era aquilo que eu queria fazer." (Participante 2)

O gostar do que faz tem relação com a identificação com o trabalho, de sentir satisfação em exercer a sua atividade. Gostar do que faz "constitui-se em elemento protetor do trabalhador, contribuindo para realização de um trabalho orientado pela finalidade projetada para cada atividade de trabalho" (Lima; Pires; Forte \& Medeiros, 2014, p. 21).

Esta identificação com o trabalho corrobora com o sentimento de participante do processo, no qual o trabalhador percebe a sua atuação diante o processo de transformação. Assim, o trabalhador não se reconhece apenas como um executor de tarefas delegadas e realizadas de forma alienadas (Lima et al, 2014).

\section{8 - Utilidade do Trabalho}

Os participantes relataram vivências de prazer relacionadas à utilidade do seu trabalho, relacionada aos desafios e aprendizados, conforme se evidencia nos exemplos a seguir:

"[...] Eu gosto dessa resoluções de problemas, de chegar ali e ter um problema novo, todo dia diferente, propor soluções diferentes, às vezes, pro mesmo problema, discutir essas soluções, implantar essas soluções pro cliente, isso pra mim é motivação." (Participante 3) 
“[...] quando tem um problema grande e eu consigo lá e resolver dá uma satisfação maior do que entregar um material ou terminar uma funcionalidade. Quando é uma coisa difícil uma coisa que eu nunca tinha feito e eu consigo fazer me dá mais satisfação." (Participante 7)

Quando o trabalhador enfrenta um momento difícil e consegue superar os obstáculos, esta vivência de sofrimento é subvertida em prazer (Máximo, Araújo, \& Zambroni-de-Souza, 2014). Nos exemplos citados pode-se verificar esta transformação realizada pela mobilização subjetiva, pois os trabalhadores relatam desenvolver suas tarefas e criar soluções através da inteligência prática, o que favorece o reconhecimento e o sentido do trabalho.

9 - Reconhecimento dos clientes e da profissão

Evidenciou-se que a satisfação demonstrada pelos clientes constitui-se em uma vivência de prazer para os trabalhadores, propiciada pelo reconhecimento de seus esforços. Referido por Dejours como necessário para que haja sentido e prazer no trabalho, o reconhecimento foi verbalizado pelos participantes do presente estudo, sobretudo em relação ao julgamento da utilidade. O qual se refere à contribuição técnica, social e econômica e é enunciado pela hierarquia, subordinados ou clientes. (Martins, 2014).

Ao pesquisar trabalhadores terceirizados da área de TI na câmara dos deputados, Martins (2014) apontou que a contribuição pelo julgamento de utilidade manifestada pelos clientes, configura-se como razão para seguirem trabalhando e ressignificando suas vivências de sofrimento. O que vai ao encontro do apontado pelos participantes:

"[...] Eu fico bem contente quando a gente recebe os elogios do cliente porque a gente vê o que a gente fez, todos os esforço teve resultado. Então, isso me deixa bem feliz assim, que é o reconhecimento do cliente, da empresa também, aquelas coisas que a gente luta pra fazer." (Participante 5)

"[...] assim, tipo assim, bah, eu fiz isso as pessoas gostaram do meu trabalho aplaudiram ele e eu consegui fazer sabe! Isso é bem importante!” (Participante 6)

De acordo com a PdT, o trabalho pode ser fonte de emancipação e realização pessoal, dependendo da dinâmica entre a contribuição que o trabalhador oferece e sua retribuição (Dejours \& Abdoucheli, 1994). Neste processo dialético ocorrerão vivências 
de prazer no trabalho, conforme demonstrado pelos entrevistados, porém estas jamais são definitivas, estarão constantemente se modificando e necessitam de atenção.

\section{0 - Sofrimento}

Para Dejours (2004), o trabalho causa sofrimento, logo que o sofrimento faz parte da condição humana. Devido à existência de um hiato entre o trabalho real e o prescrito. No entanto, o profissional pode transformar este sofrimento em criativo, defender-se dele ou o seu resultado pode ser patológico. No primeiro caso, o profissional necessita de criatividade para enfrentar às atividades laborais reais que podem estar associadas a conflitos, pressões e condições precárias, transformando-as ou ressignificando-as. Já, a falta de recursos e significados ao trabalho, pode acarretar no sofrimento psíquico e patológico.

\section{1 - Sobrecarga de Trabalho}

Os entrevistados entendem que a categoria profissional deles está sujeita a um trabalho que exige muita concentração e criatividade. As atividades laborais desta categoria dependem muito do raciocínio lógico e resolutivo dos trabalhadores, que necessitam estar focados na realização das suas tarefas. Fonseca, Neves, Amador e Kirst (2008) apontam que o trabalhador de TI vive cotidianamente sob níveis exacerbados de estresse, devido a prazos acirrados, à alta carga laboral diária e à exigência de criar soluções criativas para os softwares. Esta premissa é evidenciada na seguinte fala:

"[...] a gente não acha a solução de jeito nenhum e pode passar horas e horas que tu não vai achar aquela solução, porque tu cabeça tá tão estressada e tão focada em resolver o problema que ela tá tão preocupada, que tu não consegue pensar em outras soluções." (Participante 10)

Tal contexto laboral exige do profissional um alto nível de capacidade intelectual e responsabilidade, causando sobrecarga de trabalho e preocupações, o que tende a elevar o esgotamento nesta profissão. Tal ambiente também é permeado por pressões constantes, prazos acirrados e competitivos de entregas de softwares e relações de trabalho hostis (Ferreira, 2006). As atividades estão demasiadamente relacionadas às competências dos 
trabalhadores estarem ativos full time. Esta exigência é um processo que altera a vida do profissional dentro e fora do trabalho (Franco et al, 2010).

Segundo Antunes e Praun (2015), os trabalhadores que atuam em organizações que adotam como ferramenta de trabalho recursos tecnológicos estão expostos à flexibilização e à intensificação do ritmo de suas atividades. Os processos de trabalho estão, cada vez mais, multifuncionais, com times interdependentes e com pressão voltada para o aumento da produtividade. Condizente a isto, os participantes entrevistados alegam seu trabalho ser seguido de carga horária excessiva, atividades exigem altas demanda de trabalho, gerando estresse e impactos na saúde:

“[...] projeto 'a vai demorar 3 meses, a beleza vocês tem 2 para fazer' tipo isso vai gerando muito estresse a gente vai trabalhando todo dia até mais tarde tem que trabalhar fim de semana. Até várias vezes emendei vários finais de semana. [...] acaba afetando diretamente a qualidade porque com uma pessoa cansada ela não consegue render o mesmo tempo/qualidade do que quando ela está descansada. Sempre vai rolando estresse e ai vai girando mais bugs (referindo-se a erros). $\mathrm{O}$ estresse vai ficando maior, daí começa a ter intrigas na equipe de teste, análise, desenvolvimento, isso é bem ruim." (Participante 1).

As empresas que atuam com TI ganham destaque considerando a nova reconfiguração do trabalho que institui, o atual modelo de trabalho de sobrecarga e de maior exigência (Antunes \& Praun, 2015). O sofrimento do trabalhador está atrelado ao medo de não conseguir desenvolver suas demandas, por falta de capacidade (Monteiro \& Jacoby, 2013).

\section{2 - Pressão por resultados}

Possuir prazos determinados para a entrega de produção dos projetos torna-se um facilitador para a pressão laboral. O trabalho desenvolvido sob pressão e a falta de liberdade para escolher as atividades, geralmente, ocasiona em profissionais adoecidos. De acordo com esta perspectiva, apontada pelos entrevistados, o cotidiano do trabalho provoca a sensação de tempo comprimido, densidade das atividades e respostas imediatas às demandas do mercado:

"Mas existe sim uma pressão pra que a gente entregue as coisas no prazo, faça um esforço extra, coisas assim.” (Participante 7) 
“[...] tu tem que entregar tal dia e por mais que tu diga 'tá mas eu não vou conseguir' [...] aí chega lá no final vê que não dá, ai faz as horas extras e aí vira aquele círculo." (Participante 2)

Segundo Antunes e Praun (2015), as empresas de terceirização são marcadas pelas jornadas prolongadas, ritmos intensos de trabalho, níveis altos de rotatividade (turn over), entre outras. A pressão laboral que os profissionais relatam está atrelada a falta de planejamento dos processos de trabalho, a carga elevada de trabalho, a exigência de desempenho e às próprias ideologias e expectativas. Os entrevistados são cobrados pelos prejuízos causados, acarretando na busca por resultados de alta performance:

"Já tive situações de acontecer certas coisas que, às vezes, geraram prejuízos pra empresa. Receber uma folha com todo prejuízo, largar na minha mesa [...] fiquei bastante triste com o acontecimento porque na hora ali eu fiquei triste. Essa clareza, às vezes, a gente dá e a pessoa 'há não vou mostrar pra ele vê que né, que o erro dele gerou isso daqui, que deu prejuízo pra empresa'. Por achar isso de repente, a pessoa achou que não faria mal, mas eu me senti bastante, vamos dizer assim, bastante pressionado na época. Porque eu nunca recebi de volta, assim quanto eu deu pra empresa, mas eu recebi o quanto a empresa perdeu por mim [...]." (Participante 7)

A responsabilidade em ter que assumir para si os problemas do trabalho, muitas vezes, é uma coerção à perfeição humana (Franco et al, 2010). A competitividade do mercado assume uma ideologia pela excelência (Dejours, 2004), que visa à perfeição dos serviços, ignorando os limites dos trabalhadores (Franco et al, 2010). Trata-se de uma violência à saúde mental do trabalhador que necessita cumprir obrigatoriamente aos prazos determinados, caso contrário, são cobrados.

\section{3 - Controle}

A falta de liberdade de escolha faz com que os profissionais obrigam-se a executar as tarefas fora das suas jornadas de trabalho, pois se sentem encarregados do processo de trabalho. Este sentimento é estimulado pela autonomia controlada, o que favorece o alcance das metas empresariais. As organizações veiculam valores que refletem nas práticas dos profissionais, disfarçando a dominação estabelecida aos trabalhadores 
(Franco, Druck, \& Seligmann-Silva, 2010). Os participantes relatam como se sentem em relação a serem incubidos/responsabilizados pelos resultados de seus trabalhos:

"A gente sai daqui e, muitas vezes, acaba não falando, a gente acaba pensando. Fica no pensamento: 'bah tenho que resolver isso, tenho que resolver aquilo [...]." (Participante 7)

"Me afeta porque, sou meramente um peão de desenvolvedor, sou um desenvolvedor de nada aqui, não posso opinar, não sou eu que bato o martelo. Então tu te senti impotente, tu quer resolver, tu enxerga que as coisas não estão daquele jeito, então esse sentimento de impotência em frente a isso tá, pode mudar." (Participante 8).

A cultura empresarial do profissional bem-sucedido segundo Bendassolli (2005) é aquele que com sua capacidade e eficiência consegue superar os seus limites. Nesta perspectiva, a organização exige cada vez mais do trabalhador excelência, na qual passa a ser responsável integral por seus êxitos e fracassos.

Os profissionais desenvolvedores de softwares frisam a sua responsabilização pelos resultados, em tal acepção, impera o controle da liberdade ao final da sua jornada de trabalho, que é limitada pelas obrigações que o trabalho exige. Esta limitação lhes conduz ao excesso de esforço, sobrecarga, um ambiente de trabalho repleto de tensão, cobrança, concorrência e desgaste, o qual pode contribuir para o adoecimento do trabalhador (Bendassolli, 2005).

\section{4 - Condições de trabalho deficientes}

Não ter condições adequadas de equipamentos, que são ferramentas essenciais para a execução do trabalho, causa sofrimento para os participantes. A precarização das condições de trabalho está associada à lógica da acumulação flexível de capital (Dejours, 1999).

“[...] eu tô cansado de horas, porque a máquina é lenta tenho dificuldade de trabalhar com ela. [...] minhas ferramentas não tem suporte pra isso entendeu. $\mathrm{O}$ mínimo que eu deveria ter na empresa é um top de linha. Eu trabalho com isso, nós vendemos isso, então eu preciso ter um top de linha principalmente pra gente poder trabalhar. A partir do momento que eu entro em um (computador) inferior, que não é adequado às minhas necessidades, daí é um sentimento que gera, daí não vou ficar trabalhando até mais tarde pra atender, pra eles poderem ter um 
projeto, se eu não tenho suporte pra isso. É frustrante nesse sentido." (Participante 7)

\section{5 - Falta de reconhecimento financeiro}

Os profissionais relatam a baixa remuneração na empresa, como um indicador para o desprazer e insatisfação. Os entrevistados consideram não receberem justamente pelo seu trabalho, assim, a falta de retribuição financeira contingente ao trabalho executado contribui para o sofrimento dos profissionais. O reconhecimento é frequentemente tratado como elemento-chave da relação do sujeito com o trabalho e a organização, com repercussões nos processos motivacionais e na visão de valorização do trabalhador (Bendassolli, 2012).

O reconhecimento está associado ao desejo de retribuição pela contribuição dada pelo indivíduo, pelo seu engajamento, sua subjetividade e inteligência dedicadas ao seu trabalho (Lima, 2013). Conforme detalhado nas falas dos entrevistados:

"Empresa ideal pra se trabalhar, eu acho que é a empresa que eu sou reconhecido pelo aquilo que eu faço, que eu possa fazer parte daquele negócio como um todo. Por exemplo, nós trabalhamos aqui parecendo uns loucos! Entendo que teria que ter assim uma motivação muito maior pra trabalhar. Se tivesse uma participação de lucros, porque se eu faço meu trabalho que realmente foi bom, eu mereço. [...] as pessoas que saem, antes pedem um aumento negado, e ai quando a pessoa vai sair colocam uma faca no pescoço [...].” (Participante 7)

“[...] desprazer, infelizmente na nossa área ainda é o salário. [...], é bem ruim quando tu vê colegas bons saindo, porque a empresa não reconheceu como deveria. Isso acho bem ruim, é um grande desprazer."(Participante 4)

O descontentamento dos profissionais em relação ao reconhecimento financeiro é evidente, no qual há excesso de trabalho e pouca participação dos lucros. Este cenário, para o setor das empresas de TI, pode ser mais prejudicado com a Reforma Trabalhista (Lei n.13.467/2017), que abre um leque de possibilidades de flexibilizações e acordos entre empregador e trabalhador, como por exemplo, o Trabalho Intermitente e o Tele trabalho. 


\section{Considerações finais}

Este estudo se propôs a compreender as vivências de prazer e sofrimento no trabalho de profissionais da área de TI. A empresa que os entrevistados trabalham é voltada para estrutura de trabalho de outsourcing, o que para estes profissionais é atraente e desafiador. Os profissionais desenvolvedores de software necessitam ser dinâmicos e proativos. O seu trabalho é prazeroso por envolver o desafio de solucionar problemas, pela dinâmica de um trabalho vivo e por sentirem-se reconhecidos pelos clientes.

Os entrevistados identificaram que recebem salários inferiores ao do mercado de trabalho e que possuem sobrecarga laboral, atividades full time, responsabilidade excessiva e necessidade de acompanhar as inovações tecnológicas. Estas evidências são apontadas como fatores que thes causam sofrimento. $O$ processo de trabalho caracterizado pela sobrecarga, ritmo acelerado e prazos apertados corrobora para o desencadeamento do estresse ocupacional, esgotamento, alteração no humor, dores de cabeça e insônia nos trabalhadores.

Com a finalidade de potencializar vivências de prazer e assim promover saúde, identifica-se a necessidade de investir no reconhecimento do trabalhador, o qual poderá ser fonte de satisfação, autoestima, engajamento e motivação. Além disso, o fortalecimento de espaços de discussão genuínos pode propiciar a circulação da fala e fomentar a cooperação e o coletivo de trabalho. Torna-se relevante apontar que esta pesquisa teve como limite ser realizada em apenas uma empresa e, portanto, sugere-se o desenvolvimento de novos estudos em outras instituições.

\section{Referências}

Almeida, L. R. S., Batista, S. S., \& Cabral, A. P. P. S. (2015). O outsourcing como ferramenta estratégica nas mudanças de paradigmas organizacionais. Revista Veredas Favip, 8(2), 103-119. $\quad$ Retrieved from http://veredas.favip.edu.br/ojs/index.php/veredas1/article/viewFile/310/322.

Antunes, R., \& Praun, L. (2015). A sociedade dos adoecimentos no trabalho. Serviço Social \& Sociedade, 123, 407-427. doi:10.1590/0101-6628.030.

Bardin, L. (2011). Análise de conteúdo. São Paulo: Edições Setenta/Almedina Brasil. 
Bendassolli, P. F. (2005). Fator Humano: Cultura da Performance. GV-Executivo. V.3, n. 4, 45-48.

Bendassolli, P. F. (2012). Reconhecimento no Trabalho: perspectivas e questões contemporâneas. Psicologia em Estudo, 17(1), 37-46. Retrieved from www.scielo.br/pdf/pe/v17n1/v17n1a04.pdf.

Castro, T. G., Abs, D., \& Sarriera, J. C. (2011). Análise de conteúdo em pesquisas de Psicologia. Psicologia: Ciência e Profissão, 31(4), 814-825. doi: 10.1590/S141498932011000400011.

Dejours, C. (1997). O fator humano. Rio de Janeiro: Editora Fundação Getúlio Vargas.

Dejours, C. (2004). Subjetividade, trabalho e ação. Revista Produção, 14(3), 27-34. doi: 10.1590/S0103-65132004000300004.

Dejours, C. (2008). A avaliação do trabalho submetida a prova do real - críticas aos fundamentos da avaliação. In L. Sznelwar., F. Mascia (Orgs.). Trabalho, tecnologia e organização (pp. 31-90). São Paulo: Blucher.

Dejours, C. (2011). A Banalização da Injustiça Social. 7. ed. Rio de Janeiro: FGV.

Dejours, C., \& Abdoucheli, E. (1994). Itinerário teórico em psicopatologia do trabalho. In C. Dejours, E. Abdoucheli, C. Jayet. Psicodinâmica do Trabalho: Contribuições da Escola Dejouriana à análise da relação prazer, sofrimento e trabalho (pp. 119-145). São Paulo: Atlas.

Ferreira, A. P. C. (2006). Tecnologia de Informação, controle e mundo do trabalho: Pensar tecnologia na ótica do trabalhador. Revista Eletrônica de Ciências Sociais, 11, 14-24. Retrieved from http://www.cchla.ufpb.br/caos/n11/02.pdf.

Fonseca, T. M. G., Neves, J. M., Amador, F. S., \& Kirst, P. G. (2008). Dos modos de existência das tecnologias: um trabalho sem fim. Fractal: Revista de Psicologia, 20(2), 503-518. Retrieved from http://www.scielo.br/pdf/fractal/v20n2/15.pdf.

Franco, T., Druck, G., \& Seligmann-Silva, E. (2010). As novas relações de trabalho, o desgaste mental do trabalhador e os transtornos mentais no trabalho precarizado. Revista Brasileira de Saúde Ocupacional, 35(122), 229-248. doi: 10.1590/S030376572010000200006.

Freitas, L. G., \& Facas, E. P. (2013). Vivências de prazer-sofrimento no contexto de trabalho dos professores. Estudos e Pesquisas em Psicologia, 13(1), 7-26. Retrieved from http://www.revispsi.uerj.br/v13n1/artigos/pdf/v13n1a02.pdf.

Lei n 13.467, de 13 de julho de 2017 (2017). Reforma Trabalhista: Altera a Consolidação das Leis do Trabalho (CLT), aprovada pelo Decreto-Lei no 5.452, de 1o de maio de 1943, a fim de adequar a legislação às novas relações de trabalho. Brasília: Presidente da República. Recuperado em 21 de setembro, de 2018, de http://www.jurisciencia.com/vademecum/lei-13-467-13-de-julho-de-2017-reformatrabalhista/3515/

Lima, J. C., \& Oliveira, D. R. (2017). Trabalhadores digitais: as novas ocupações no trabalho informacional. Sociedade e Estado, 32(1), 115-143. doi: 10.1590/s010269922017.3201006. 
Lima, L. d, Pires, D. E. P. d, Forte, E. C. N \& Medeiros, F. (2014). Job satisfaction and dissatisfaction of primary health care professionals. Esc. Anna Nery, Jan./Mar.; 18(1):17-24.

Lima, S. C. C. (2013). Reconhecimento no Trabalho. In F. O. Vieira, A. M. Mendes, \& A. R. C. Merlo (Orgs.). Dicionário Crítico de Gestão e Psicodinâmica do Trabalho (pp. 351-355). Curitiba: Juruá Editora.

Martins, M. (2014). A psicodinâmica do reconhecimento no trabalho de informática de terceirizados e concursados da câmara dos deputados. E-legis, 14, 46-63. Retrieved from http://e-legis.camara.leg.br/cefor/index.php/e-legis/article/viewFile/186/229.

Máximo, T. A. C. O., Araújo, A. J. S., \& Zambroni-de-Souza, P. C.. (2014). Vivências de sofrimento e prazer no trabalho de gerentes de banco. Psicologia: Ciência e Profissão, 34(1), 96-111. doi: 10.1590/S1414-98932014000100008.

Mendes, A. M. (Org.). (2007). Psicodinâmica do trabalho: teoria, método e pesquisas. 1. ed. São Paulo: Casa do Psicólogo.

Merlo, A. R. C. (2015). Clínica da Psicodinâmica do Trabalho. Revista Polis e Psique, 5(3), 179-197. Retrieved from http://pepsic.bvsalud.org/pdf/rpps/v5n3/n5a11.pdf.

Monteiro, J. K., \& Jacoby, A. R. (2013). Sobrecarga de Trabalho. In F. O. Vieira, A. M. Mendes, \& A. R. C. Merlo (Orgs.). Dicionário Crítico de Gestão e Psicodinâmica do Trabalho (pp. 405-408). Curitiba: Juruá Editora.

Pacheco, W., Pereira Jr., C., Pereira, V. L. S. V., \& Pereira Filho, H. V. (2005). A era da tecnologia da informação e da comunicação e a saúde do trabalhador. Revista Brasileira de Medicina do Trabalho, 3(2), 114-122. Retrieved from http://www.anamt.org.br/site/upload_arquivos/revista_brasileira_de_medicina_do_tr abalho - volume 3 201220131511537055475.pdf.

Pinheiro, M. H. B. (2011). A representação social do profissional analista de sistemas da informação: relato de pesquisa. Revista Ibero-Americana de Ciência da Informação, 4(1), 93-114. Retrieved from http://www.brapci.inf.br/v/a/13085.

Rosenfield, C. (2011). Trabalho decente e precarização. Tempo Social, Revista de Sociologia da USP, 23(1), 247-268. Retrieved from https://www.revistas.usp.br/ts/article/view/12660.

Silva, R. L., \& Siluk, J. C. M. (2007). Terceirização: o outsourcing como ferramenta estratégica. Trabalho de Conclusão de Curso, Graduação em Administração, UNIFRA.

Tittoni, J., \& Nardi, H. (2011). Subjetividade e Trabalho. In A. D. Cattani, L. Holzmann (Orgs.). Dicionário de Trabalho e Tecnologia (pp. 277-280). 2. ed. Porto Alegre: Zouk. 